\title{
Quantification of Phycocyanin in Inland Waters through Remote Measurement of Ratios and Shifts in Reflection Spectral Peaks
}

\author{
Gibeom Nam ${ }^{1}{ }^{\mathbb{D}}$, Hyunjoo Shin ${ }^{1} \mathbb{D}, \operatorname{Rim} \mathrm{Ha}^{2}{ }^{2}$ Hyunoh Song ${ }^{1}$, Jaehyun Yoo ${ }^{1}$, Hyuk Lee ${ }^{1}$, Sanghyun Park ${ }^{1}$, \\ Taegu Kang ${ }^{1}$ and Kyunghyun Kim ${ }^{1, * \mathbb{D}}$ \\ 1 The National Institute of Environmental Research, 42 Hwangyeong-ro, Seo-gu, Incheon 22689, Korea; \\ gbnam@korea.kr (G.N.); max0216@korea.kr (H.S.); roiz@korea.kr (H.S.); jhyoo0127@korea.kr (J.Y.); \\ ehyuk72@korea.kr (H.L.); pbaby75@korea.kr (S.P.); taegu98@korea.kr (T.K.) \\ 2 The Seoul Institute of Technology, 37 Maebongsan-ro, Mapo-gu, Seoul 03909, Korea; rim486@sit.re.kr \\ * Correspondence: matthias@korea.kr; Tel.: +82-32-560-7353
}

check for

updates

Citation: Nam, G.; Shin, H.; Ha, R.; Song, H.; Yoo, J.; Lee, H.; Park, S.;

Kang, T.; Kim, K. Quantification of Phycocyanin in Inland Waters through Remote Measurement of Ratios and Shifts in Reflection Spectral Peaks. Remote Sens. 2021, 13, 3335. https://doi.org/10.3390/ rs13163335

Academic Editor: Ana C. Brito

Received: 21 April 2021

Accepted: 18 August 2021

Published: 23 August 2021

Publisher's Note: MDPI stays neutral with regard to jurisdictional claims in published maps and institutional affiliations.

Copyright: (c) 2021 by the authors. Licensee MDPI, Basel, Switzerland. This article is an open access article distributed under the terms and conditions of the Creative Commons Attribution (CC BY) license (https:// creativecommons.org/licenses/by/ $4.0 /)$.

\begin{abstract}
This study introduces a semi-empirical algorithm to estimate the extent of the phycocyanin (PC) concentration in eutrophic freshwater bodies; this is achieved by studying the reflectance characteristics of the red and near-red spectral regions, especially the shifting of the peak near $700 \mathrm{~nm}$ towards longer wavelengths. Spectral measurements in a darkroom environment over the pure-cultured cyanobacteria Microcystis showed that the shift is proportional to the algal biomass. A similar proportional trend was found from extensive field measurement data. The data also showed that the correlation of the magnitude of the shift with the PC concentration was greater than that with chlorophyll- $a$. This indicates that the characteristic can be a useful index to quantify cyanobacterial biomass. Based on these observations, a new PC algorithm was proposed that uses the remote sensing reflectance of the peak band around $700 \mathrm{~nm}$ and the trough band around $620 \mathrm{~nm}$, and the magnitude of the peak shift near $700 \mathrm{~nm}$. The efficacy of the algorithm was tested with 300 sets of field data, and the results were compared to select algorithms for the PC concentration prediction. The new algorithm performed better than the other algorithms with respect to most error indices, especially the mean relative error, indicating that the algorithm can reduce errors when PC concentrations are low. The algorithm was also applied to a hyperspectral dataset obtained through aerial imaging, in order to predict the spatial distribution of the PC concentration in an approximately $86 \mathrm{~km}$ long reach of the Nakdong River.
\end{abstract}

Keywords: hyperspectral remote sensing; cyanobacteria; phycocyanin; spectral shape algorithm; water quality

\section{Introduction}

Cyanobacteria, also known as blue-green algae, are the most common organisms that form blooms in eutrophic inland waters. Some cyanobacterial species can be highly harmful to aquatic species and even humans [1-3]. Increasing incidence of cyanobacteriadominated blooms owing to the increase in anthropogenic nutrient inputs and perhaps enhanced by climate warming has become a critical global issue [4,5]. This problem can be more serious in countries such as the Republic of Korea, which depend heavily on surface water resources for their drinking water.

Reliable algal monitoring is a key factor for the effective control of cyanobacterial bloom. Traditional methods to identify cyanobacterial profusion include cell counting under a microscope, high-pressure liquid chromatography (HPLC), and fluorometric methods. These methods provide relatively accurate results, but are labor-intensive and inadequately cover spatio-temporally heterogeneous algal blooms [6,7]. Remote sensing techniques can be effective in this regard, as they can cover a broad geographical range; 
they also have an advantage with respect to temporal repeatability [8-10]. Remote sensing is especially suited to monitoring cyanobacteria because of the surface concentration of the cells and definitive photosynthesizing pigments [11-14]. Among the pigments, phycocyanin (PC), an accessory pigment of chlorophyll, is unique to cyanobacteria, and thus has been commonly used as an indicator of cyanobacterial presence in algal remote sensing [14-16].

There have been many research studies during the past few decades dedicated to quantifying cyanobacterial biomass in turbid inland waters using remote sensing techniques. The methods used in these studies include base-line algorithms [17], bandratio algorithms [13,18], semi-analytical algorithms [11,14], and quasi-analytical algorithms $[12,19,20]$. Most studies have focused on the wavelengths near $620 \mathrm{~nm}$, the absorption trough for PC [21], while some algorithms have concentrated on the PC florescence peak near $650 \mathrm{~nm}$.

Meanwhile, the reflectance in the red-wavelength region, which is less sensitive to colored dissolved organic matter (CDOM), has been commonly utilized to quantitatively detect algal biomass [22]. The characteristics of the reflectance spectra near $700 \mathrm{~nm}$ have been well recognized; the height of the peak and its shift towards longer wavelengths are positively correlated with chlorophyll-a (Chl-a) concentrations [23-27]. These changes in characteristics are the result of complex relationships among the particulate backscattering from cellular materials, chlorophyll absorption, and fluorescence in the red-wavelength band [22]. As algal biomass increases, stronger backscattering results in higher reflectance, while growing absorption in the vicinity of $685 \mathrm{~nm}$ naturally shifts the reflectance peak to longer wavelengths despite the higher fluorescence at the same wavelengths.

These characteristics of the spectral peak can be particularly useful for estimating cyanobacterial biomass because backscattering can be greater for cyanobacteria, especially Microcystis, the most common and problematic cyanobacterial species, owing to their spherical shape, small size, and the presence of internal gas vacuoles [28,29]. Moreover, absorption in water dominated by small-sized cyanobacteria can be higher than that in water dominated by large-sized eukaryotic phytoplankton with the same level of chlorophyll [30]. Despite all the advantages, these characteristics have been utilized merely for the direct estimation of cyanobacterial biomass. This is because most studies used multispectral data that only provided select wavelength bands close to the peaks, but not bands at the exact peak locations.

In this study, a novel algorithm to predict PC concentrations, which is a simple function of the reflectance band ratio for 620 and $700 \mathrm{~nm}$, and the magnitude of the peak shift, is suggested. This study utilized the shift in peak near $700 \mathrm{~nm}$ for remotely quantifying cyanobacterial biomass, using hyperspectral data to overcome the aforementioned hurdle regarding data availability. A functional relationship representing the magnitude of the peak shift to the PC concentration was formulated from a laboratory culturing experiment. Specifically, Microcystis aeruginosa, which frequently appears as the dominant species in the Nakdong River in Korea during summer, was pure-cultured first and spectral measurements were conducted in a darkroom environment. Its parameters were calibrated using field monitoring data from a river where $M$. aeruginosa frequently emerges as the dominant species during summer. The performance of the suggested algorithm was evaluated by comparison with select algorithms that have been successful in previous PC concentration predictions.

\section{Materials and Methods}

\subsection{Study Area and Data}

Originating from the central-eastern mountainous region of South Korea, the Nakdong River flows southward until it meets the South Sea (Figure 1). Within the watershed with a total area of $23,380 \mathrm{~km}^{2}$, there are two metropolitan cities, one located along the middle stretch of the river, and the other located further downstream close to the river mouth. Several small and large industrial complexes are also distributed along the course of the 
river, discharging a significant pollution load into it. The climate of the area within this watershed is characterized as East-Asian monsoon climate, with frequent heavy rainfall from late June to mid-July, followed by a long dry period that normally lasts until late August with high temperatures (maximum of approximately $40{ }^{\circ} \mathrm{C}$ ) during summer. Since the completion of a major engineering project on the river, during which the river became deeper and wider thanks to the construction of eight large weirs, the river has frequently experienced thermal stratification and significant cyanobacterial blooms during dry periods in summer, leading to the depletion of dissolved oxygen at the river bottom and supersaturation at the surface. Thus, systematic monitoring is critical for cyanobacterial bloom control in this area.

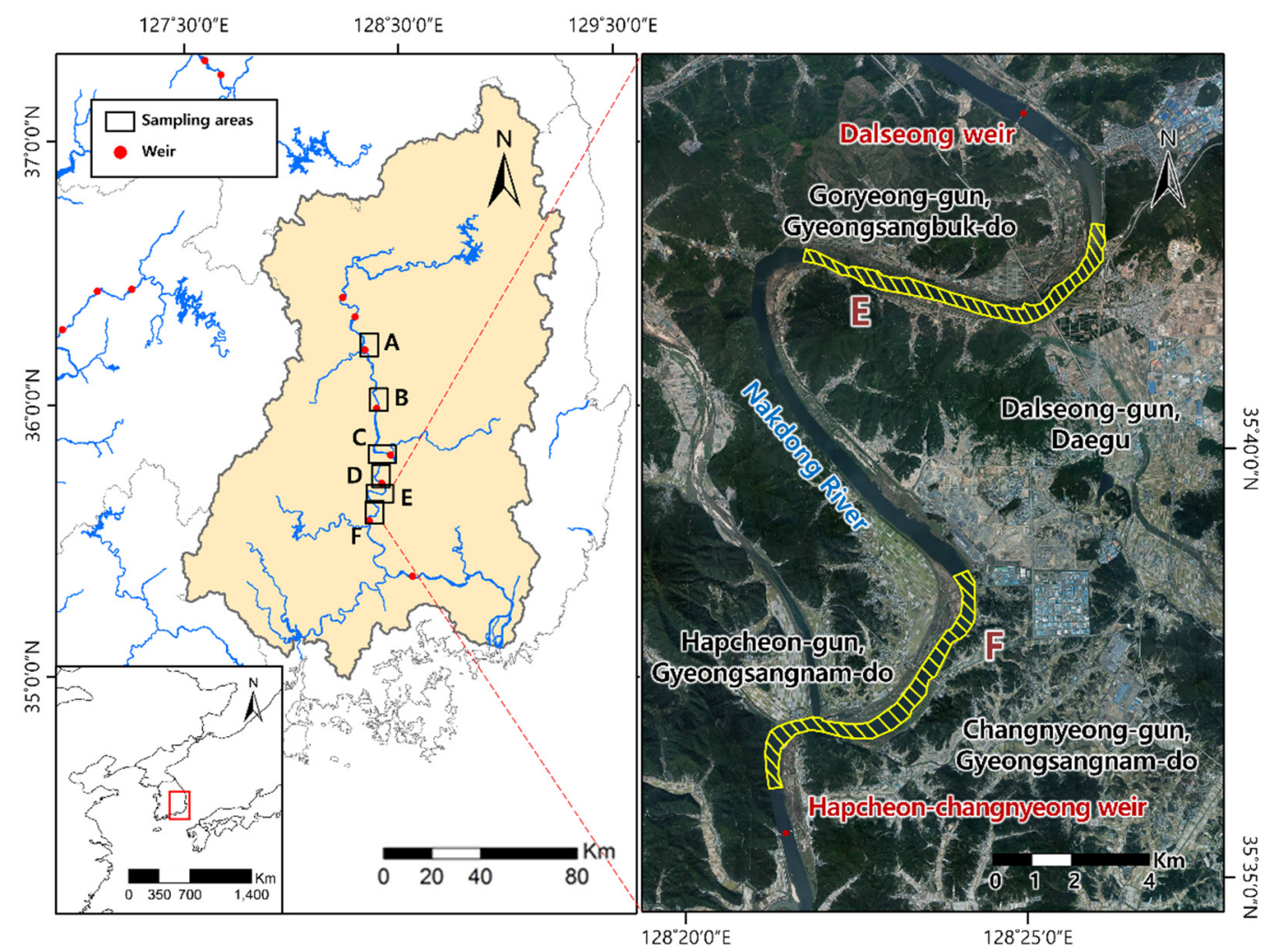

Figure 1. River sections (marked as rectangles) representing the sampling zones along the Nakdong River (left). An enlarged image of zones $\mathrm{E}$ and $\mathrm{F}$ is presented (right).

The middle stretch of the Nakdong River was selected as the study site; this site is divided into reaches, with each reach defined by two adjoining weirs of the eight large weirs constructed in series along the main channel. There are six sampling zones, each located in a different river reach between two adjacent weirs, except the last two, which are located in the same reach (Figure 1). Zone A is located upstream of the Gumi Weir (GM), while zone B is located upstream of the Chilgok Weir (CG), upstream of which a large industrial complex discharges its effluent. Zone $C$ is located upstream of the GangjeongGoryeong Weir (GG), and zone D is located upstream of the Dalseong Weir (DS), which receives significant pollutant loads from the metropolitan city of Daegu. The last two zones, $\mathrm{E}$ and $\mathrm{F}$, are located in the reach upstream of the Hapcheon-Changnyeong Weir (HC).

\subsubsection{Field Data Sampling}

On-site sampling and radiance measurements were conducted on the six sampling zones during the cyanobacterial blooming periods (June to November) from 2015 to 2018. We collected 300 water samples from points distributed among the sampling areas (each of the sampling points of the sampling zones is shown in Figure S1 in the Supplementary Data). For each sampling, surface water was collected from the layer extending from the 
surface to a depth of $0.5 \mathrm{~m}$. The sample was divided into several volumes for different purposes. To measure PC concentrations, the $5 \mathrm{~L}$ sub-sample (the volume varied from 5 to $20 \mathrm{~L}$ based on the phytoplankton concentration) was concentrated to $125 \mathrm{~mL}$ (a detailed explanation of the pigment extraction is presented in Section 2.1.3); the $2 \mathrm{~L}$ and $50 \mathrm{~mL}$ sub-samples were used to determine Chl- $a$ concentration and cell density, respectively. The $50 \mathrm{~mL}$ samples were immediately preserved on-site using Lugol's iodine solution ( $2 \%$ final concentration), and all samples were stored in a box with ice and transferred to a laboratory for further analysis.

\subsubsection{Remote Sensing Reflectance Retrieval}

Reflectance measurements were conducted at each sampling point. The Fieldspec- 4 spectroradiometer (ASD Inc., Boulder, CO, USA), which can detect a wavelength range of $350-2500 \mathrm{~nm}$, was used for the reflectance measurements. The downwelling irradiance $\left(E_{d}\right)$ was measured using a remote cosine receptor (RCR). The water surface and sky radiances $\left(L_{T}, L_{s k y}\right)$ were measured with a bare fiber. The measurement geometries of $L_{T}$ and $L_{s k y}$ were maintained within a zenith angle of $135^{\circ}$ and $45^{\circ}$, respectively. The relative azimuth angle of the sensors to the sun was maintained at $135^{\circ}$ to minimize sun glint and shading interference [31,32].

The remote sensing reflectance $R_{r s}(\lambda)$ on the surface water was defined as follows

$$
R_{r s}(\lambda)=\frac{L_{w}(\lambda)}{E_{d}(\lambda)}\left[\mathrm{sr}^{-1}\right]
$$

where $E_{d}(\lambda)$ is the downwelling irradiance from the sun and $L_{w}(\lambda)$ is the water-leaving radiance corrected for the sky effect at the surface water. $L_{w}(\lambda)$ is calculated from

$$
L_{w}(\lambda)=L_{T}(\lambda)-\rho \cdot L_{S k y}(\lambda)
$$

where $L_{T}(\lambda)$ is the total upwelling water surface radiance and $L_{\text {sky }}(\lambda)$ is the sky radiance. $\rho$ is the skylight correction factor, which is defined as 0.025 according to a field wind speed of less than $5 \mathrm{~m} / \mathrm{s}$ [33].

\subsubsection{Pigment Extraction}

For determination of the PC concentration, the pigment was extracted using the freezing and thawing technique from [34], and the concentration was calculated using the equation from [35]. The PC extraction was based on a previously published method [36]. Pre-concentrated samples were homogenized with a $200 \mathrm{~W}$ Ultra-Sonicator (SIBATA Inc., Seoul, Korea). Thirty milliliters of each homogenized sample was centrifuged at $4000 \mathrm{rpm}$ and $5{ }^{\circ} \mathrm{C}$ for $15 \mathrm{~min}$. The supernatants were discarded. Phosphate buffer $(5 \mathrm{~mL})$ was added to the pellets. The samples were frozen at $-20{ }^{\circ} \mathrm{C}$ for $24 \mathrm{~h}$ and then thawed at room temperature to lyse the algal cells. A shaking incubator (JEIOTECH Inc., Daejeon, Korea) was used to extract the PC pigment at $150 \mathrm{rpm}$ for $15 \mathrm{~min}$. The samples were centrifuged under the same conditions as above to separate the supernatants. The optical density of the supernatant samples was measured using a Cary-300 ultraviolet-visible spectrophotometer (Agilent Inc., Santa Clara, CA, USA). Then, the PC concentration was estimated as follows:

$$
\mathrm{PC}\left(\mathrm{mg} / \mathrm{m}^{3}\right)=\frac{O D_{620}-\left(0.474 \times O D_{652}\right)}{5.34}
$$

where $O D_{\mathrm{w}}$ is the optical density at the specific wavelength $w$.

Chl- $a$ concentrations were analyzed by the standard method for the examination of water and wastewater [37]. The water samples were filtered using a glass microfiber filter (Whatman) with a pore size of $0.7 \mu \mathrm{m}$. The residues were ground in 9:1 acetone/water and stored in a $-4{ }^{\circ} \mathrm{C}$ refrigerator for $24 \mathrm{~h}$. After the samples were centrifuged at $500 \times g$ and $20^{\circ} \mathrm{C}$ for $20 \mathrm{~min}$, the optical densities of the sample supernatants were measured using a 
Cary-300 ultraviolet-visible spectrophotometer (Agilent Inc., Santa Clara, CA, USA). The Chl- $a$ concentration was estimated as follows:

$$
\mathrm{Chl}-a\left(\mathrm{mg} / \mathrm{m}^{3}\right)=\frac{\left(11.64 X_{1}-2.16 X_{2}+0.10 X_{3}\right) \times V_{1}}{V_{2}}
$$

where $X_{1}, X_{2}$, and $X_{3}$ are $\left(O D_{663}-O D_{750}\right),\left(O D_{645}-O D_{750}\right)$, and $\left(O D_{630}-O D_{750}\right)$, respectively. $V_{1}$ and $V_{2}$ represent the supernatant and the volume of filtrate, respectively.

Cell density was measured with a Sedgwick Rafter counting chamber under a magnification of $\times 200-\times 400$ and calculated as cells $/ \mathrm{mL}$.

\subsection{Darkroom Spectral Measurements}

Spectral measurements were conducted on various concentrations of pure-cultured cyanobacterial species under darkroom conditions to identify the location shift of the peak near $700 \mathrm{~nm}$ proportional to the amount of cyanobacterial biomass (Figure 2). $M$. aeruginosa, the dominant cyanobacterial species during algal bloom periods in the Nakdong River, was pure-cultured in flasks in CB medium. The cells in exponential phase were diluted to one million cells per $\mathrm{mL}$ (sample VI in Table 1). This was further diluted to compose the final set of six samples with different biomass levels of the PC concentration (Table 1). The concentrations of the samples were determined to be relatively high to consider the very weak illumination in the darkroom; otherwise, the reflectance signal would be undetectable.
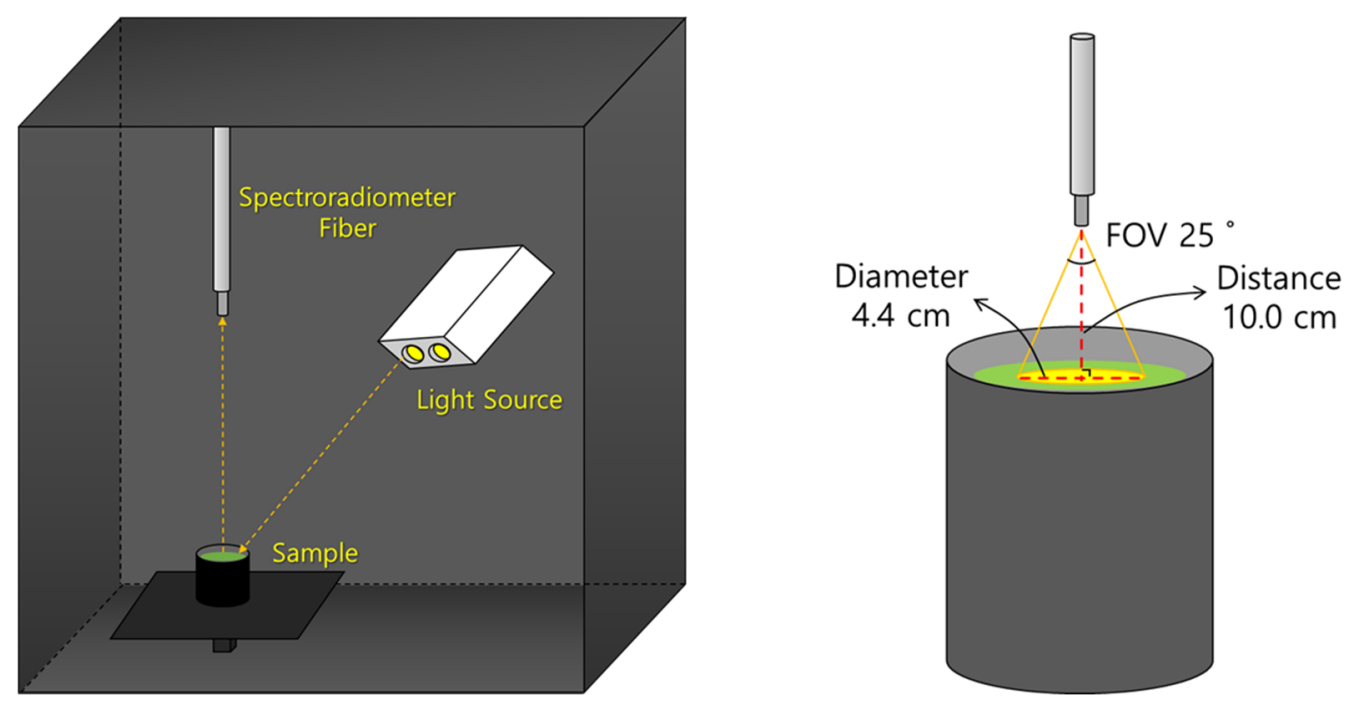

Figure 2. Darkroom setup for the spectral measurements of the algae; (left) schematic of the darkroom experimental design; (right) sensing geometry of each sample in the beaker.

Table 1. Sample design for spectral measurements in a darkroom setup.

\begin{tabular}{ccccccc}
\hline & I & II & III & IV & V & VI \\
\hline Phycocyanin $\left(\mathrm{mg} / \mathrm{m}^{3}\right)$ & 89.1 & 178.2 & 890.8 & 2227.0 & 3117.8 & 8908.1 \\
\hline Cell counts $\left(\times 10^{3}\right.$ cells $\left./ \mathrm{mL}\right)$ & 10 & 20 & 100 & 250 & 350 & 1000 \\
\hline
\end{tabular}

The spectral measurements were conducted using the ASD Fieldspec- 4 spectroradiometer, the same one used for the field measurements, which provides radiance values within a wavelength range from 500 to $800 \mathrm{~nm}$ in $1 \mathrm{~nm}$ intervals. Each sample was placed in a $100 \mathrm{~mL}$ beaker, the interior of which was painted matte black to minimize the effects of extraneous light reflections [38-40]. The light source inside the darkroom consisted of three $35 \mathrm{~W}$ halogen lamps, fixed at a $45^{\circ}$ angle to the water surface of the beaker, minimizing the shadow of the sensor inside the beaker and light reflectance from the surface of the water. 
The distance between the sensor and beaker was set at $10 \mathrm{~cm}$ considering the field of view (FOV) of the sensor and the diameter of the beaker. The distance between the lamps and beaker was set at $50 \mathrm{~cm}$.

In the darkroom experiment, the positions of the target and light source were fixed and there was no effect of weather. Therefore, the reflectance of the sample can be calculated by the following Equation (5).

$$
R_{r s}(\lambda)=\frac{L_{s}(\lambda)}{L_{d}(\lambda)}\left[\mathrm{sr}^{-1}\right]
$$

where $L_{S}(\lambda)$ is the sample radiance and $L_{d}(\lambda)$ is the reference radiance from a diffuse plate with 99\% reflectance (SRT-99-100 Reflectance Target, Labsphere, North Sutton, NH, USA).

\subsection{Development of the Band-Ratio and Peak-Distance (BRPD) Algorithm}

In a typical spectral curve observed for eutrophic inland waters, distinct features in the red and near-red region related to cyanobacteria include the trough near $620 \mathrm{~nm}$ corresponding to maximum absorption by the PC $[13,18,20]$ and the peak near $700 \mathrm{~nm}$ due to backscattering from cellular particles. The trough can deepen as cyanobacterial biomass increases not only owing to the increase in absorption by the PC, but also owing to the rise of the peak adjacent to $650 \mathrm{~nm}$ from increased PC fluorescence [41]. Similarly, the peak near $700 \mathrm{~nm}$ can rise as a result of stronger backscattering from the increased number of cellular particles; in addition, the peak tends to shift towards longer wavelengths with increased cell density, as mentioned previously. Therefore, the amount of cyanobacterial biomass in the water can be represented by the product of the ratio of the reflectance corresponding to the peak to that of the trough, and the magnitude of the peak shift, which is incorporated in the algorithm proposed in this study.

The algorithm adopted the band-ratio of the reflectance at the peak near $700 \mathrm{~nm}$ $R_{r s}\left(700_{\text {peak }}\right)$ to the reflectance at the trough near $620 \mathrm{~nm} R_{r s}\left(620_{\text {trough }}\right)$, which is similar to the ratio used in the semi-analytical embedded band-ratio algorithm of [14]. The magnitude of the peak shift is defined as the wavelength difference of the near $700 \mathrm{~nm}$ peak of the current measurement and the minimum wavelength among all the measurements $\left(\Delta \lambda_{\text {peak }}\right)$. The difference value can be normalized to the maximum difference max $\left(\Delta \lambda_{\text {peak }}\right)$, that is, the wavelength difference of the maximum wavelength and the minimum wavelength of the $700 \mathrm{~nm}$ peak among all the measurements. This normalization was applied to avoid the index value being determined only by the peak shift term in exponential form because the value of the peak shift term is sometimes significantly larger than the band ratio term. Therefore, the algorithm proposed to estimate cyanobacterial biomass can be expressed by the product of the band-ratio and the peak shift (Equation (6)), which we call the band-ratio and peak-distance (BRPD) index.

$$
\mathrm{PC} \propto \frac{R_{r s}\left(700_{\text {peak }}\right)}{R_{r s}\left(620_{\text {trough }}\right)} \times\left(\frac{\Delta \lambda_{\text {peak }}}{\max \left(\Delta \lambda_{\text {peak }}\right)}\right)^{a}
$$

where $a$ indicates a power constant that needs to be calibrated with the observed data. In this study, we used 200 out of 300 field datasets for calibration, and the remaining 100 datasets for validation; the datasets were grouped in such a way that data from high to low concentrations were evenly distributed between the two groups. The BRPD was developed as a semi-empirical algorithm using the wavelength associated with algal pigments and the power constant was empirically determined.

\subsection{Model Evaluation}

The performance of the proposed algorithm was evaluated by comparing it with the selected existing algorithms, HU10 [11], MM09 [42], and Si05 [14], which showed relatively high accuracy in the review by [42]. Their equations are listed in Table 2. 
Table 2. Algorithms from existing studies for estimating the PC concentration used for comparison with the proposed algorithm.

\begin{tabular}{cc}
\hline HU10 (Hunter et al., 2010) & $P C \propto\left[R_{r s}^{-1}\left(\lambda_{615}\right)-R_{r s}^{-1}\left(\lambda_{600}\right)\right] \times R_{r s}\left(\lambda_{725}\right)$ \\
\hline MM09 (Ogashawara et al., 2013) & $P C \propto R_{r s}\left(\lambda_{724}\right) / R_{r s}\left(\lambda_{600}\right)$ \\
\hline Si05 (Simis et al., 2005) & $P C \propto R_{r s}\left(\lambda_{709}\right) / R_{r s}\left(\lambda_{620}\right)$ \\
\hline Note: These indices are ranked as the three most accurate among the PC algorithms in [42].
\end{tabular}

The same calibration and validation procedures were applied to the four algorithms, including the BRPD algorithm proposed in this study. The calibration for each algorithm utilized the same calibration dataset for model development through linear regression analysis between the index and PC concentration. Then, each algorithm was validated with the same validation dataset.

\subsection{Error Analysis}

To compare the estimated and observed values, we used $R$ square, mean relative error (MRE), root-mean-square error (RMSE), and mean absolute error (MAE). They were calculated as follows:

$$
\begin{gathered}
R^{2}=1-\frac{\sum_{i=1}^{n}\left(Y_{i}-E_{i}\right)^{2}}{\sum_{i=1}^{n}\left(Y_{i}-\bar{Y}\right)^{2}} \\
\text { RMSE }=\sqrt{\frac{1}{n} \sum_{i=1}^{n}\left(Y_{i}-E_{i}\right)^{2}} \\
\text { MAE }=\frac{1}{n} \sum_{i=1}^{n}\left|Y_{i}-E_{i}\right| \\
\text { MRE }=\frac{1}{n} \sum_{i=1}^{n} \frac{\left|Y_{i}-E_{i}\right|}{Y_{i}}
\end{gathered}
$$

where $Y_{i}$ and $E_{i}$ denote the observed and estimated values, respectively, for the $i$ th measurement of the PC concentration. $Y$ is the mean of the observed values. $\left|Y_{i}-E_{i}\right| / Y_{i}$ in Equation (10) is the relative error. We used these multiple error statistics because they have different characteristics. Among the four statistics, RMSE and MAE are absolute measures of the goodness of fit, while $R$ square and MRE are relative measures. Moreover, because $R$ square and RMSE are calculated using the square of error, they tend to give larger penalization to big prediction errors, while MRE does this to small observed values. MAE deals with all errors equivalently.

\subsection{BRPD Application to Aerial Hyperspectral Images}

The proposed BRPD algorithm was applied to the data obtained through airborne hyperspectral remote sensing from an approximately $86 \mathrm{~km}$ long reach in the mid to downstream part of the Nakdong River to assess its applicability for remote monitoring of cyanobacteria. The aerial sensing operation was conducted on 11 August 2016 using the Eagle hyperspectral image sensor (Specim Inc., Oulu, Finland) mounted under a Cessna aircraft. As sufficient numbers of water sample datasets, whose collection times matched exactly with the aerial sensing times, were not available, the estimated values of the PC concentration using the airborne hyperspectral image could not be evaluated with the point sampling data. Therefore, we decided to compare the overall distribution of the PC concentration to the corresponding red-green-blue (RGB) images from the digital mapping camera installed together with the image sensor. The ATCOR-4 was used to perform atmospheric correction of the images [43], and the BRPD algorithm was applied after masking the river portion. 


\section{Results and Discussion}

\subsection{Spectral Characteristics Observed from Darkroom Experiment}

The results of the reflectance spectral measurements in the darkroom experiment on the $M$. aeruginosa samples, which cover a range of biomasses representing various PC concentrations, are shown in Figure 3. The overall reflectance spectra showed an increasing tendency as the PC concentration increased. The authors of [44] indicated that spectroscopy of a water body dominated by algae shows two peaks and two troughs in the $600-750 \mathrm{~nm}$ range. As peaks and troughs are clearly observed in the results of the darkroom experiment, the experimental environment was considered suitable. The first trough near $620 \mathrm{~nm}$ and the second one near $675 \mathrm{~nm}$ represent the PC and Chl- $a$ pigment absorptions, respectively [18,41,45-47]. The first peak near $650 \mathrm{~nm}$ appears due to the relative reflectance trough from the two pigments [18]. The second peak appears near $700 \mathrm{~nm}$, representing the reflectance from scattering by suspended matter including algae $[18,48]$. The peak near $700 \mathrm{~nm}$ showed an interesting characteristic of migrating in the direction of the long wavelength with respect to the increase in PC concentration, while the other peaks showed very little migration (within $5 \mathrm{~nm}$ ) [23-27]. From the results, Equation (6) was formulated by selecting the best functional relationship to the experimental data among several different candidate forms (Figure S2).

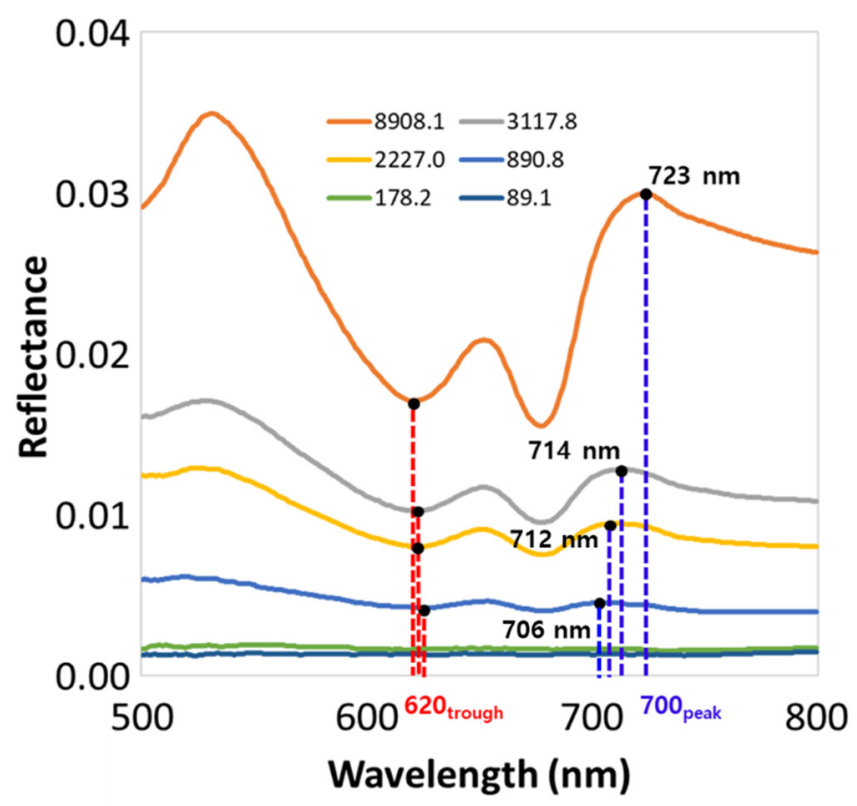

Figure 3. Spectral measurement results from the darkroom experiment. The reflectance spectra of samples with six different PC levels show a strong trend of peak shift being proportional to PC concentration in cultured Microcystis aeruginosa.

\subsection{Results of BRPD Application to Field Data}

The descriptive statistics for the PC and Chl- $a$ data are shown in Table S1, including the mean, maximum, and minimum. The PC concentration ranged from 0.1 to $333.7 \mathrm{mg} / \mathrm{m}^{3}$, with a mean of $25.8 \mathrm{mg} / \mathrm{m}^{3}$. The highest concentrations of PC and Chl- $a$ were measured on 25 August 2016 at the Hapcheon-Changnyeong area, with concentrations of 333.7 and $243.9 \mathrm{mg} / \mathrm{m}^{3}$, respectively.

Figure 4 shows the relationship between the near $700 \mathrm{~nm}$ peak shifts $\left(\Delta \lambda_{\text {peak }}\right)$ and the PC or Chl- $a$ concentrations using all 300 datasets. The peak shift showed a strong correlation with PC concentration $\left(R^{2}=0.68\right)$ and a relatively weak correlation with Chl- $a$ concentration $\left(R^{2}=0.48\right)$. The reasons for this are as follows: $(1)$ the component that has the maximum contribution to the peak is the backscattering from cellular particles, which can be greater for small-sized cyanobacteria such as Microcystis than for large-sized eukaryotic 
phytoplankton species belonging to Chlorophyceae and Bacillariophyceae [30]; and (2) distinctive characteristics of Microcystis such as its spherical shape and presence of internal gas vacuoles increase the backscattering intensity [28,29]. Microcystis is the dominating species in the Nakdong River and can represent over $90 \%$ of the total algal composition (cell counts) during summer [49]. Therefore, the trend indicated in Figure 4 implies that peak shift can be a suitable index for quantifying the PC concentration, especially when Microcystis is the dominating species.

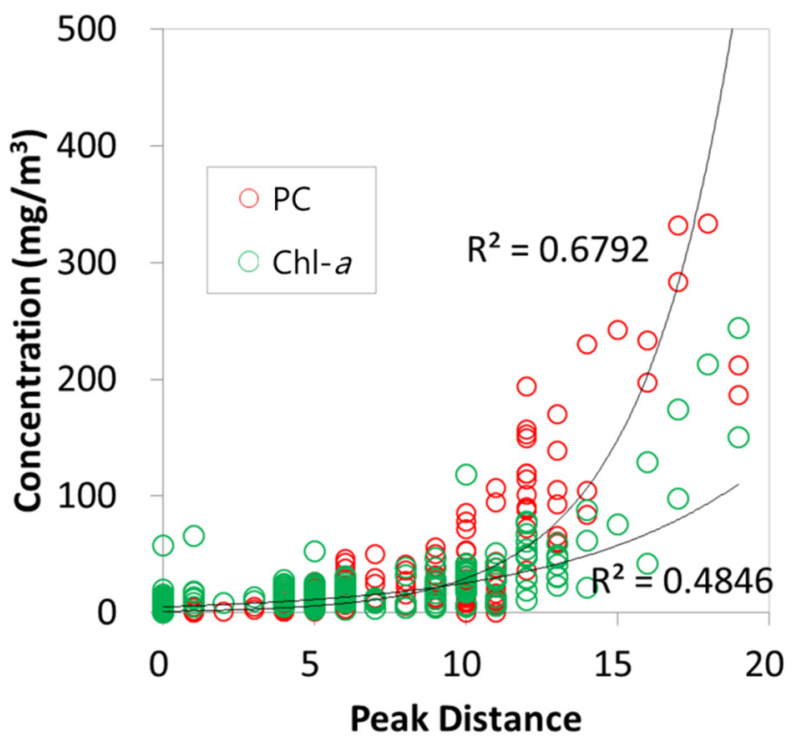

Figure 4. Relationship between the near $700 \mathrm{~nm}$ peak shift $\left(\Delta \lambda_{\text {peak }}\right)$, and phycocyanin or chlorophyll$a$ concentration.

Figure 5 shows the application of the algorithms using scatter plots of the estimated versus measured PC concentrations. The results show that BRPD performed better than the other methods with respect to all error indices, except the RMSE value, which was slightly higher than that for Si05. Particularly, the MRE of the proposed method was $177.3 \%$, which was much lower than the $635.1 \%$ of $\mathrm{Hu} 10$, the second best method in terms of MRE. A similar tendency was observed in the results using the 100 validation datasets (Figure 6). Again, BRPD was found to be better to Hu10 and MM09 with respect to all the error indices. The BRPD method showed a similar performance to Si05 in terms of RMSE and MAE, but showed a much lower MRE value.

The MRE is sensitive to the accuracy of low data values because they render the denominator of the MRE expression to be small; hence, the MRE can be large even with small variations in the numerator. Thus, the results indicate relatively high accuracy of BRPD for estimating PC concentration values when these values are low. The comparatively high accuracy of the method in regions of low PC concentrations can be confirmed by examining the variation in the relative error across the range of PC concentrations. In Figure 7 , although the relative errors (log \%) corresponding to the relatively low estimated PC concentrations were high with BRPD, they were lower than the relative errors for the other algorithms. Unlike the other algorithms, applying BRPD produced a relative error of less than 1 in the low PC concentration ranges. We inferred that such an improvement was caused by the exponential component of the equation in the BRPD algorithm, which clearly differentiates between high and low PC concentrations based on the distance at which the peak appears. Most algorithms used for estimating PC concentrations are known to have low accuracy at concentrations below $50 \mathrm{mg} / \mathrm{m}^{3}$ [12]. The authors of [14] indicated that, when the PC concentration is below $15 \mathrm{mg} / \mathrm{m}^{3}$, the results can be overestimated by 2.5 to 15 times. 

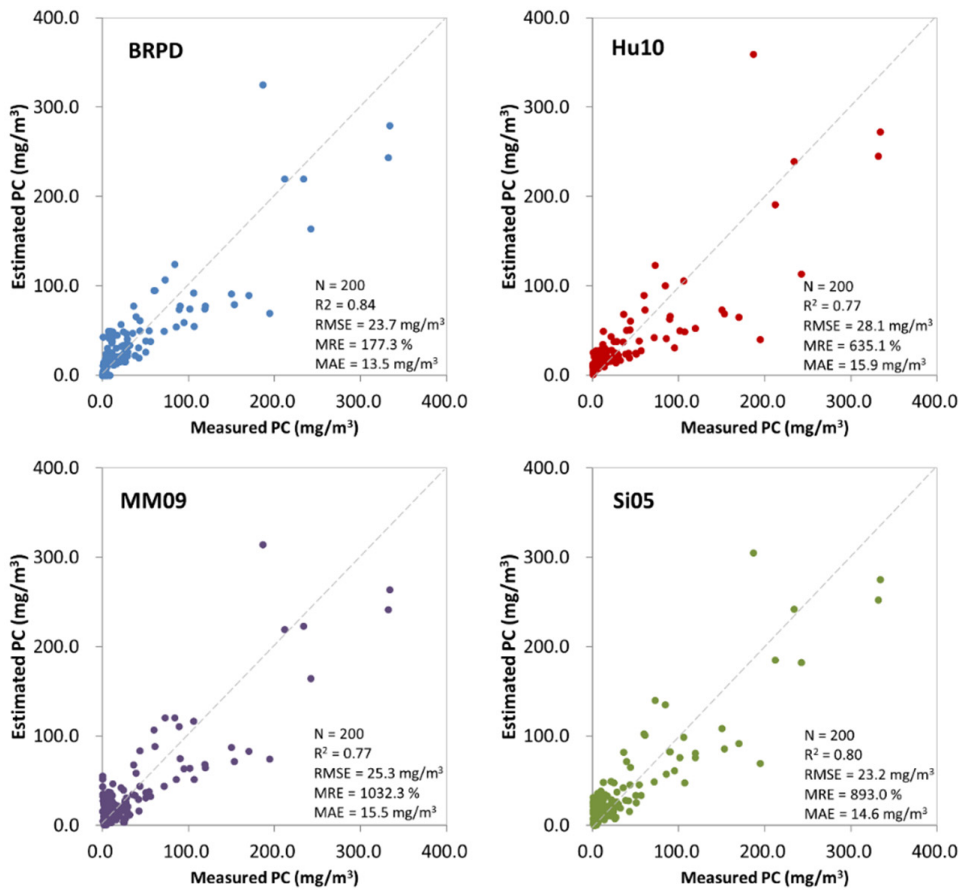

Figure 5. Results of applying four different algorithms to the calibration datasets. BRPD performed better than the other three methods in all of the error indices except RMSE, which was slightly higher than the Si05 value.
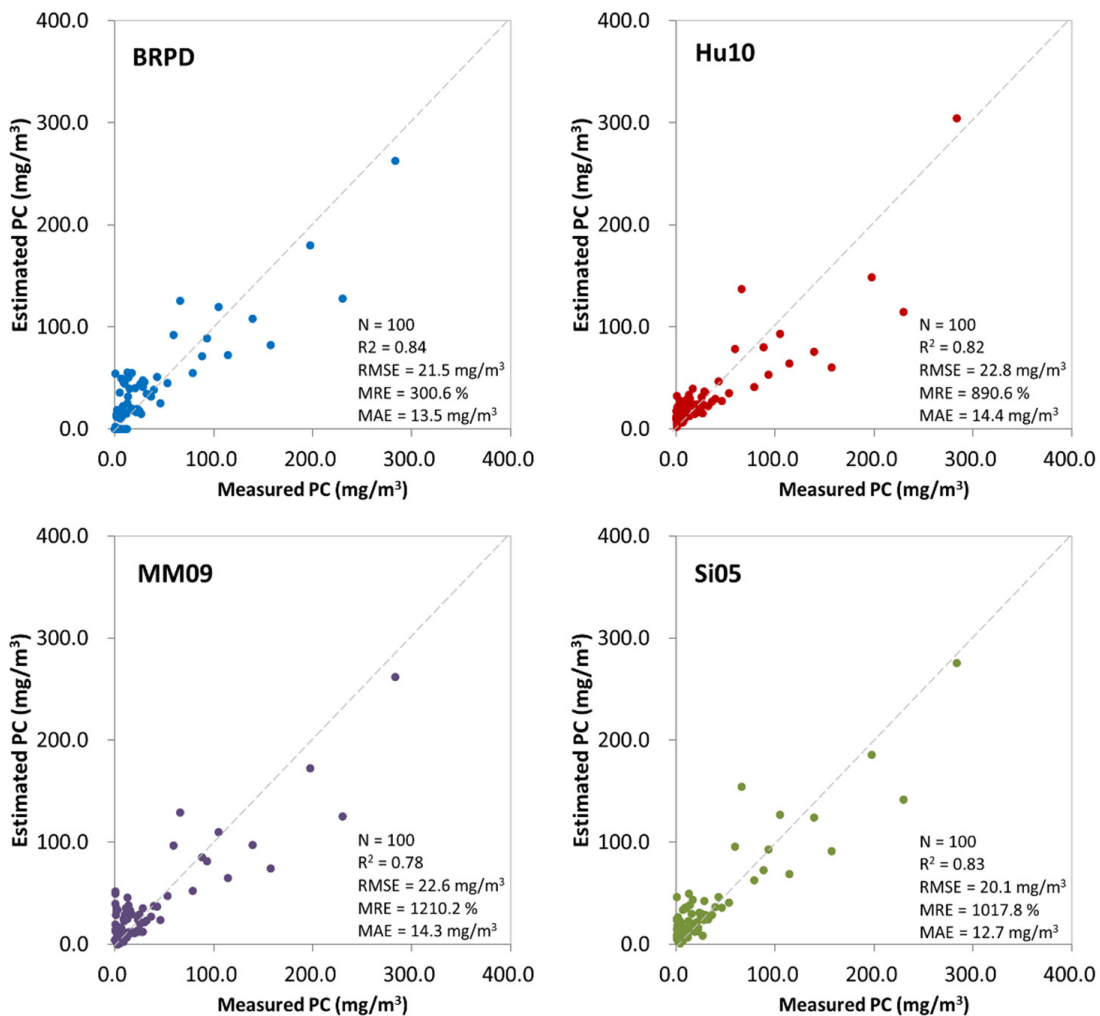

Figure 6. Results obtained by applying four different algorithms to the validation datasets. Similar to the results of the calibration case, BRPD performed better than the other three methods in all of the error indices except the RMSE and MAE values, which were slightly higher than those of Si05. 

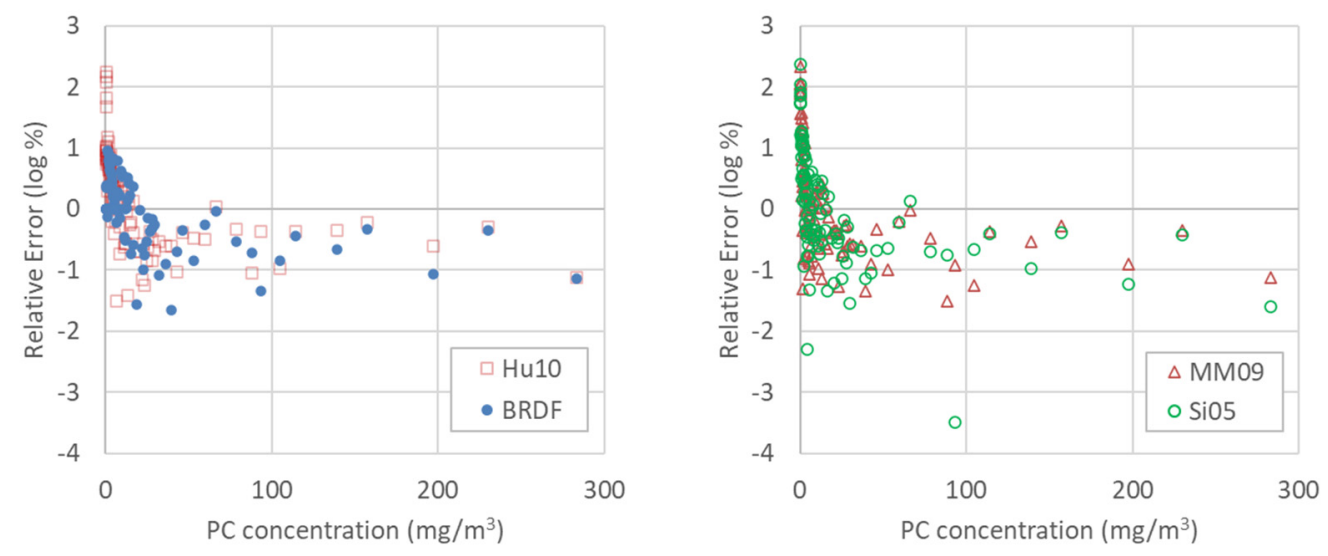

Figure 7. Comparison of relative error (log \%) for each algorithm used in this study. Blue circles, red squares, red triangles, and green circles represent errors from the BRPD, Hu10, MM09, and Si05 algorithms, respectively.

It may be argued that the improvement in the model fit by BRPD may benefit from using a wavelength-sliding algorithm that is only possible because of the hyperspectral nature of the data. This could be true because the exact wavelength of the trough near $620 \mathrm{~nm}$ and the peak near $700 \mathrm{~nm}$ could be selected for the band ratio in Equation (6), while the wavelengths of the other algorithms were fixed as in Table 2. However, some portion of the improvement should be attributed to the peak shift part in the equation. Thus, the effect of considering peak distance on the prediction accuracy was further explored by regression of only the band-ratio part of BRPD, and applying the same 200 datasets used for calibration (Figure 8). Regression was carried out to achieve the best fit. Compared with the results of BRPD in Figure 5, all other error indices were worse; the change in MRE was more prominent, being three times greater than that of BRPD. This may be a clear indication that including the shift of the reflectance peak in the algorithm can improve prediction accuracy, especially for low PC concentrations.

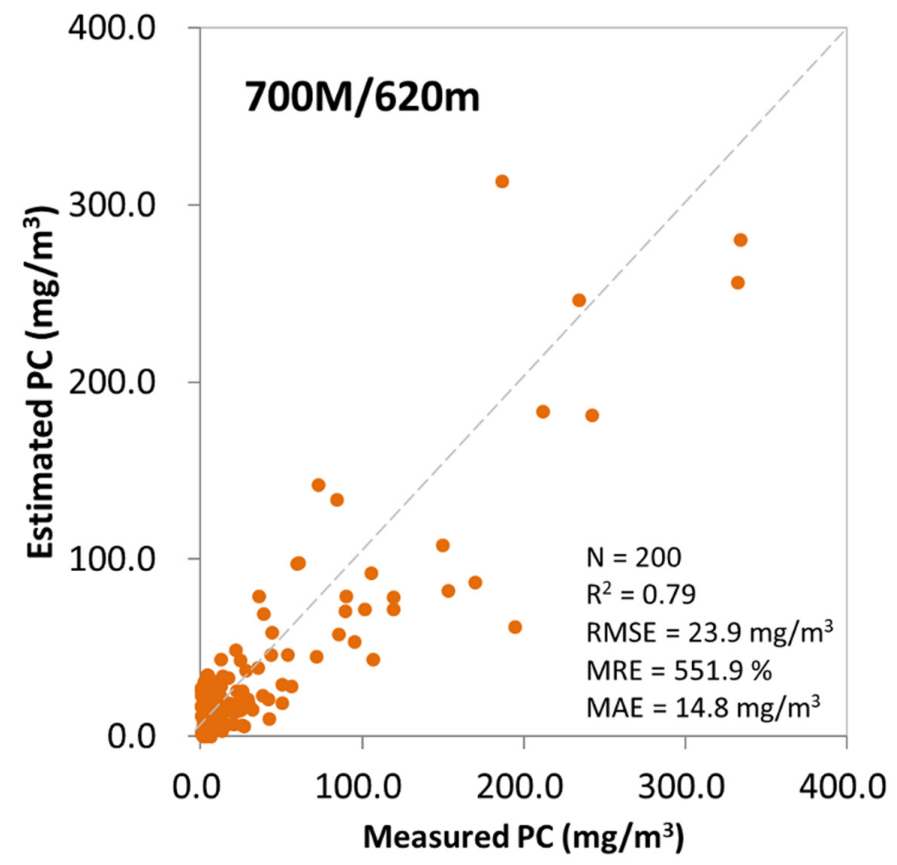

Figure 8. Results obtained by regression of only the band-ratio part of BRPD for evaluating the effect of including peak shift on prediction accuracy. The same 200 calibration datasets used in Figure 4 were used here. 


\subsection{Application of Hyperspectral Images from Remote Sensing}

Figure 9 shows that high PC concentrations were estimated in some parts of the river that are recognized as areas where frequent blooming occurs [50-52]. The distribution pattern of the PC concentrations in the areas (I) and (II) marked in the figure closely matches the distribution of algal blooms in the RGB images. High PC concentrations were found over the entire area owing to an influx of nutrients from tributaries as well as channels originating from agricultural fields at the end of the rainy season. The image of the mid- to downstream part of the Nakdong River indicated as area (II) in Figure 10 shows areas of high PC concentrations, and is an excellent record of wind-generated algal waves on the water surface.

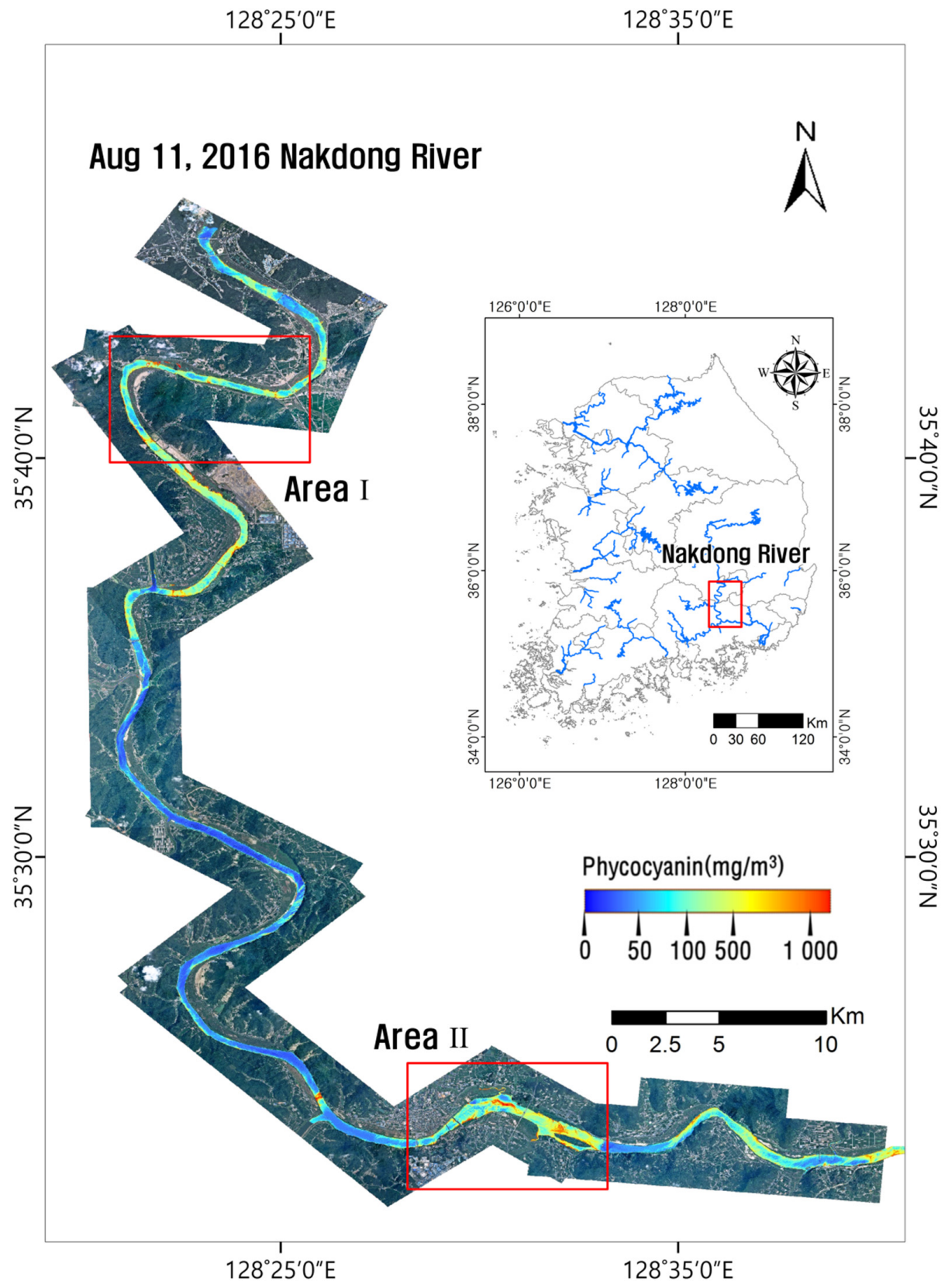

Figure 9. Spatial distribution of phycocyanin concentrations estimated using the calibrated BRPD algorithm for a mid- to downstream section of the Nakdong River based on reflectance data observed on 11 August 2016. 


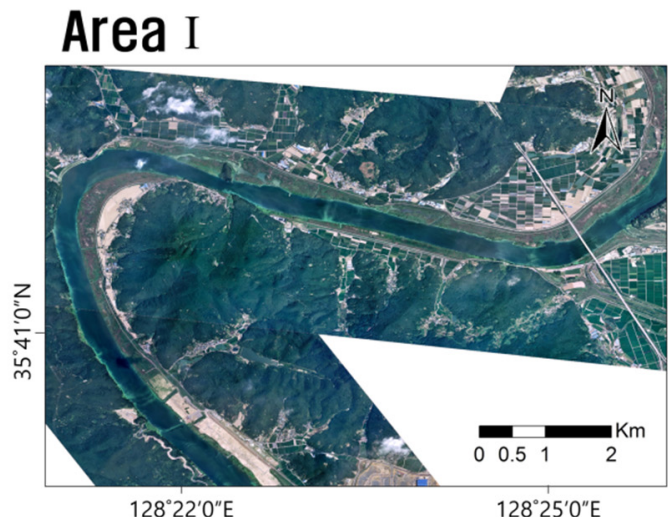

Area II

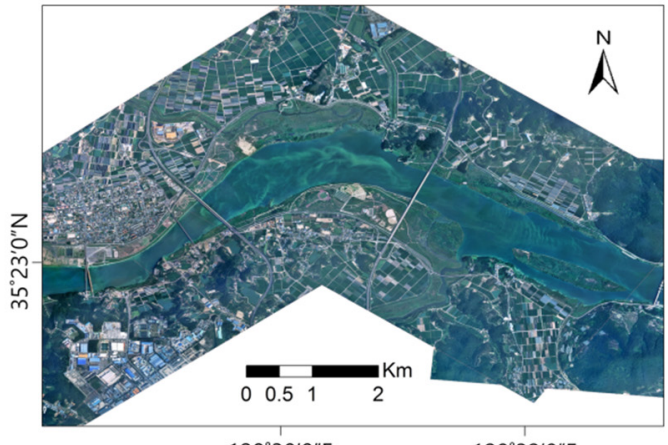

$128^{\circ} 30^{\prime} 0^{\prime \prime} \mathrm{E}$

$128^{\circ} 32^{\prime} 0^{\prime \prime} \mathrm{E}$

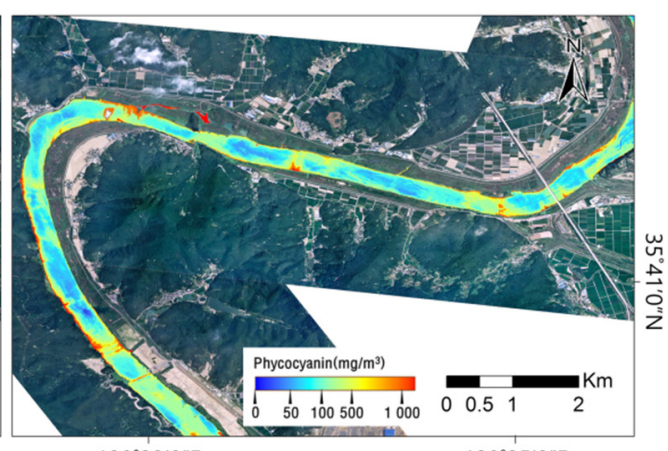

$128^{\circ} 22^{\prime} 0^{\prime \prime} \mathrm{E}$

$128^{\circ} 25^{\prime} 0^{\prime \prime} E$

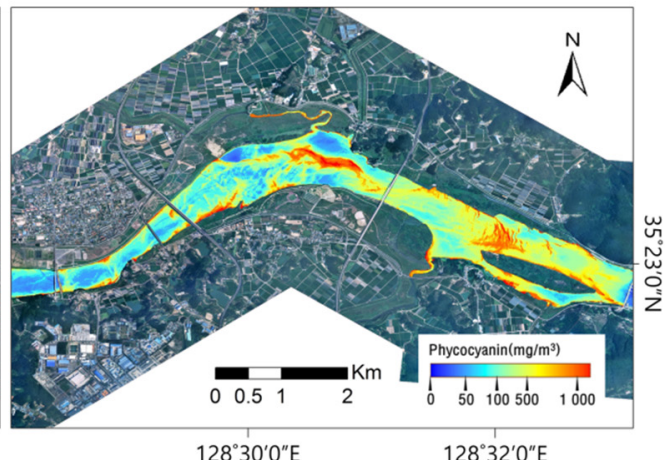

Figure 10. Comparison of estimated PC concentrations (right) and corresponding RGB images (left) at selected areas along the Nakdong River.

\section{Conclusions}

A new algorithm for the estimation of PC concentrations in eutrophic freshwater bodies, which utilizes the characteristics of reflectance spectra in red and near-red regions corresponding to algal blooms, was proposed. Among the characteristics, the magnitude of the forward shift of the peak near $700 \mathrm{~nm}$ toward longer wavelengths proportional to the cyanobacterial biomass present was considered to lead to a more accurate estimate of the PC concentration. The shift in the peak showed a strong correlation with the PC concentration and a relatively weak correlation with the Chl- $a$ concentration, suggesting that it can be a good indicator of PC concentration. The proposed algorithm performed better than the other PC estimation algorithms selected for comparison, with the peak shift component contributing significantly to the overall accuracy of the algorithm.

As hyperspectral image data become more easily available, utilizing this new technology to predict spatial distributions and concentrations of cyanobacteria with increased accuracy will become more widespread. The results of this study show that hyperspectral image data including information on the peak shift provide many opportunities to utilize detailed information on spectral characteristics corresponding to cyanobacterial blooms in developing algorithms that can predict their distribution and concentration with greater accuracy. However, the drawback of this algorithm, as is the case with some other PC estimation algorithms, is that its applicability may be limited to situations where cyanobacteria are the dominant algal class. Thus, future studies should also focus on the categorization of algal species using hyperspectral observations to overcome this drawback.

Supplementary Materials: The following are available online at https:/ / www.mdpi.com/article/ 10.3390/rs13163335/s1, Figure S1: Map of sampling points in zones A-F. The sky blue, light green, yellow, and red dots are sampling points in 2015, 2016, 2017, and 2018, respectively. Figure S2. Plot of the predicted values by candidate equations versus measured data from the lab experiment: (1) band ratio of $700_{\text {peak }} / 620_{\text {trough }}$, (2) distance of peak shifting, (3) band ratio $\times$ distance, (4) power function 
of distance, and (5) band ratio $\times$ power function of distance. As seen in the figure, model (5), which is identical to Equation (6), shows the best fit (although the $700_{\text {peak }} / 620_{\text {trough }}$ model (green dots) also showed a good fit, but was slightly worse). Note that, although samples of six different concentrations of phycocyanin were tested in the experiment (Table 1), we used only four of these concentrations above; for the other two concentrations, the reflectance signals were too weak to distinguish peaks or troughs. Table S1: Descriptive statistics of phycocyanin and chlorophyll- $a$ concentrations for the samples collected in the Nakdong River from 2015 to 2018.

Author Contributions: Conceptualization, K.K. and G.N.; methodology, K.K. and G.N.; software, R.H., H.S. (Hyunjoo Shin), J.Y., H.S. (Hyunoh Song) and G.N.; validation, K.K. and G.N.; investigation, H.L., S.P., R.H., H.S. (Hyunjoo Shin), H.S. (Hyunoh Song) and G.N.; data curation, R.H., H.S. (Hyunjoo Shin), J.Y., H.S. (Hyunoh Song) and G.N.; writing-original draft preparation, G.N.; writing-review and editing, K.K., T.K., H.L., S.P. and G.N.; visualization, R.H., H.S. (Hyunjoo Shin), J.Y. and G.N.; supervision, K.K., T.K. and H.L.; project administration, T.K., H.L. and S.P.; funding acquisition, T.K. All authors have read and agreed to the published version of the manuscript.

Funding: This research was funded by the National Institute of Environmental Research (NIER), grant number NIER-2020-01-01-011.

Conflicts of Interest: The authors declare no conflict of interest.

\section{References}

1. Millie, D.F.; Fahnenstiel, G.L.; Dyble, J.; Pigg, R.; Rediske, R.; Klarer, D.M.; Litaker, R.W.; Tester, P.A. Influence of environmental conditions on late-summer cyanobacterial abundance in Saginaw Bay, Lake Huron. Aquat. Ecosyst. Health Manag. 2008, 11, 196-205. [CrossRef]

2. Rinta-Kanto, J.M.; Konopko, E.A.; DeBruyn, J.M.; Bourbonniere, R.A.; Boyer, G.L.; Wilhelm, S.W. Lake Erie Microcystis: Relationship between microcystin production, dynamics of genotypes and environmental parameters in a large lake. Harmful Algae 2009, 8, 665-673. [CrossRef]

3. Wynne, T.T.; Stumpf, R.P.; Tomlinson, M.C.; Dyble, J. Characterizing a cyanobacterial bloom in western Lake Erie using satellite imagery and meteorological data. Limnol. Oceanogr. 2010, 55, 2025-2036. [CrossRef]

4. Paerl, H.W.; Otten, T.G. Harmful cyanobacterial blooms: Causes, consequences, and controls. Microb. Ecol. 2013, 65, 995-1010. [CrossRef] [PubMed]

5. Visser, P.M.; Verspagen, J.M.H.; Sandrini, G.; Stal, L.J.; Matthijs, H.C.P.; Davis, T.W.; Paerl, H.W.; Huisman, J. How rising CO 2 and global warming may stimulate harmful cyanobacterial blooms. Harmful Algae 2016, 54, 145-159. [CrossRef] [PubMed]

6. Dörnhöfer, K.; Klinger, P.; Heege, T.; Oppelt, N. Multi-sensor satellite and in situ monitoring of phytoplankton development in a eutrophic-mesotrophic lake. Sci. Total Environ. 2018, 612, 1200-1214. [CrossRef]

7. Schaeffer, B.A.; Schaeffer, K.G.; Keith, D.; Lunetta, R.S.; Conmy, R.; Gould, R.W. Barriers to adopting satellite remote sensing for water quality management. Int. J. Remote Sens. 2013, 34, 7534-7544. [CrossRef]

8. Bukata, R.P. Retrospection and introspection on remote sensing of inland water quality: "Like Déjà Vu All Over Again". J. Great Lakes Res. 2013, 39, 2-5. [CrossRef]

9. Mishra, S. Remote Sensing of Cyanobacteria in Turbid Productive Waters. Ph.D. Thesis, Mississippi State University, Starkville, MS, USA, 2012.

10. Palmer, S.C.J.; Kutser, T.; Hunter, P.D. Remote sensing of inland waters: Challenges, progress and future directions. Remote Sens. Environ. 2015, 157, 1-8. [CrossRef]

11. Hunter, P.D.; Tyler, A.N.; Carvalho, L.; Codd, G.A.; Maberly, S.C. Hyperspectral remote sensing of cyanobacterial pigments as indicators for cell populations and toxins in eutrophic lakes. Remote Sens. Environ. 2010, 114, 2705-2718. [CrossRef]

12. Mishra, S.; Mishra, D.R.; Lee, Z.; Tucker, C.S. Quantifying cyanobacterial phycocyanin concentration in turbid productive waters: A quasi-analytical approach. Remote Sens. Environ. 2013, 133, 141-151. [CrossRef]

13. Mishra, S.; Mishra, D.R.; Schluchter, W.M. A novel algorithm for predicting phycocyanin concentrations in cyanobacteria: A proximal hyperspectral remote sensing approach. Remote Sens. 2009, 1, 758-775. [CrossRef]

14. Simis, S.G.H.; Peters, S.W.M.; Gons, H.J. Remote sensing of the cyanobacterial pigment phycocyanin in turbid inland water. Limnol. Oceanogr. 2005, 50, 237-245. [CrossRef]

15. Duan, H.; Ma, R.; Hu, C. Evaluation of remote sensing algorithms for cyanobacterial pigment retrievals during spring bloom formation in several lakes of East China. Remote Sens. Environ. 2012, 126, 126-135. [CrossRef]

16. Ruiz-Verdú, A.; Simis, S.G.H.; de Hoyos, C.; Gons, H.J.; Peña-Martínez, R. An evaluation of algorithms for the remote sensing of cyanobacterial biomass. Remote Sens. Environ. 2008, 112, 3996-4008. [CrossRef]

17. Dekker, A.G. Detection of Optical Water Quality Parameters for Eutrophic Waters by High Resolution Remote Sensing. Ph.D. Thesis, The University of Amsterdam, Amsterdam, The Netherlands, 1993.

18. Schalles, J.F.; Yacobi, Y.Z. Remote detection and seasonal patterns of phycocyanin, carotenoid and chlorophyll pigments in eutrophic waters. Ergebnisse Der Limnologie 2000, 55, 153-168. 
19. Li, L.; Li, L.; Song, K. Remote sensing of freshwater cyanobacteria: An extended IOP Inversion Model of Inland Waters (IIMIW) for partitioning absorption coefficient and estimating phycocyanin. Remote Sens. Environ. 2015, 157, 9-23. [CrossRef]

20. Mishra, S.; Mishra, D.R. A novel remote sensing algorithm to quantify phycocyanin in cyanobacterial algal blooms. Environ. Res. Lett. 2014, 9, 114003. [CrossRef]

21. Yang, D.; Pan, D. Hyperspectral retrieval model of phycocyanin in case II waters. Chin. Sci. Bull. 2006, 51, 149-153. [CrossRef]

22. Tao, B.; Mao, Z.; Pan, D.; Shen, Y.; Zhu, Q.; Chen, J. Influence of bio-optical parameter variability on the reflectance peak position in the red band of algal bloom waters. Ecol. Inform. 2013, 16, 17-24. [CrossRef]

23. Gitelson, A.A. The peak near $700 \mathrm{~nm}$ on radiance spectra of algae and water relationships of its magnitude and position with chlorophyll concentration. Int. J. Remote Sens. 1992, 13, 3367-3373. [CrossRef]

24. Kallio, K.; Kutser, T.; Hannonen, T.; Koponen, S.; Pulliainen, J.; Vepsäläinen, J.; Pyhälahti, T. Retrieval of water quality from airborne imaging spectrometry of various lake types in different seasons. Sci. Total Environ. 2001, 268, 59-77. [CrossRef]

25. Kutser, T.; Paavel, B.; Verpoorter, C.; Ligi, M.; Soomets, T.; Toming, K.; Casal, G. Remote sensing of black lakes and using $810 \mathrm{~nm}$ reflectance peak for retrieving water quality parameters of optically complex waters. Remote Sens. 2016, 8, 497. [CrossRef]

26. Yacobi, Y.Z.; Gitelson, A.; Mayo, M. Remote Sensing of Chlorophyll in Lake Kinneret Using Highspectral-Resolution Radiometer and Landsat TM: Spectral Features of Reflectance and Algorithm Development. J. Plankton Res. 1995, 17, 2155-2173. [CrossRef]

27. Zimba, P.V.; Gitelson, A. Remote estimation of chlorophyll concentration in hyper-eutrophic aquatic systems: Model tuning and accuracy optimization. Aquaculture 2006, 256, 272-286. [CrossRef]

28. Matthews, M.W.; Bernard, S. Using a two-layered sphere model to investigate the impact of gas vacuoles on the inherent optical properties of Microcystis aeruginosa. Biogeosciences 2013, 10, 8139-8157. [CrossRef]

29. Vaillancourt, R.D.; Brown, C.W.; Guillard, R.R.L.; Balch, W.M. Light backscattering properties of marine phytoplankton: Relationships to cell size, chemical composition and taxonomy. J. Plankton Res. 2004, 26, 191-212. [CrossRef]

30. Matthews, M.W.; Bernard, S. Characterizing the absorption properties for remote sensing of three small optically diverse South African reservoirs. Remote Sens. 2013, 5, 4370-4404. [CrossRef]

31. Simis, G.H.; Ruiz-Verdu, A.; Gominguez-Gomez, J.A.; Pena-Martinez, R.; Peter, W.M.; Gons, H.M. Influence of phytoplankton pigment composition on remote sensing of cyanobacterial biomass. Remote Sens. Environ. 2007, 106, 414-427. [CrossRef]

32. Garaba, S.P.; Zielinski, O. Methods in reducing surface reflected glint for shipborne above-water remote sensing. J. Eur. Opt. Soc. Rapid Publ. 2013, 8. [CrossRef]

33. Mobley, C.D. Estimation of the remote-sensing reflectance from above-surface measurements. Appl. Opt. 1999, 38, 7442-7455. [CrossRef]

34. Sarada, R.; Pillai, M.G.; Ravishankar, G.A. Phycocyanin from Spirulina sp: Influence of processing of biomasson phycocyanin yield, analysis of efficacy of extraction methods and stability studies on phycocyanin. Process. Biochem. 1999, 34, 759-801. [CrossRef]

35. Bennett, A.; Bogorad, L. Complementary chromatic adaptation in a filamentous blue-green alga. J. Cell Biol. 1973, 58, 419-435 [CrossRef] [PubMed]

36. Ha, R.; Shin, H.; Nam, G.; Park, S.; Kang, T.; Song, H.; Lee, H. A study on comparison of phycocyanin extraction methods for hyperspectral remote sensing of cyanobacteria in turbid inland waters. J. Korean Soc. Water Environ. 2016, 32, 520-527. [CrossRef]

37. Federation, W.E.; APH Association. Standard Method for the Examination of Water and Wastewater; American Public Health Association (APHA): Washington, DC, USA, 2005.

38. Han, L.; Rundquist, D.C.; Liu, L.L.; Fraser, R.N.; Schalles, J.F. The spectral responses of algal chlorophyll in water with varying levels of suspended sediment. Int. J. Remote Sens. 1994, 15, 3707-3718. [CrossRef]

39. Gin, K.Y.H.; Kou, S.T.; Lin, I.I. Study of the effects of suspended marine clay on the reflectance spectra of phytoplankton. Int. J. Remote Sens. 2002, 23, 2163-2178. [CrossRef]

40. Oyama, Y.; Matsushita, B.; Fukushima, T.; Nagai, T.; Imai, A. A new algorithm for estimating chlorophyll-a concentration from multi-spectral satellite data in case II waters: A simulation based on a controlled laboratory experiment. Int. J. Remote Sens. 2007, 28, 1437-1453. [CrossRef]

41. Rowan, K.S. Photosynthetic Pigments of Algae; Cambridge University Press: New York, NY, USA, 1989.

42. Ogashawara, I.; Mishra, D.R.; Mishra, S.; Curtarelli, M.P.; Stech, J.L. A performance review of reflectance based algorithms for predicting phycocyanin concentrations in inland waters. Remote Sens. 2013, 5, 4774-4798. [CrossRef]

43. Richter, R.; Center, R.S.D. ATCOR: Atmospheric and Topographic Correction; German Aerospace Center, Mars: Oberpfaffenhofen, Germany, 2004.

44. Li, L.; Sengpiel, R.E.; Pascual, D.L.; Tedesco, L.P.; Wilson, J.S.; Soyeux, E. Using hyperspectral remote sensing to estimate chlorophyll-a and phycocyanin in a mesotrophic reservoir. Int. J. Remote Sens. 2010, 31, 4147-4162. [CrossRef]

45. Gitelson, A.A.; Schelles, J.F.; Rundquist, D.C.; Schiebe, F.R.; Yacobi, Y. Comparative reflectance properties of algal cultures with manipulated densities. J. Appl. Phycol. 1999, 11, 345-354. [CrossRef]

46. Gitelson, A.A.; Yacobi, Y.Z.; Schalles, J.F.; Rundquist, D.C.; Han, L.; Stark, R.; Etzion, D. Remote estimation of phytoplankton density in productive waters. Arch. HydrobioI. Spec. Issues Advanc. Limnol. 2000, 55, 121-136.

47. Rundquist, D.C.; Han, L.; Schalles, J.F.; Peake, J.S. Remote measurement of algal chlorophyll in surface waters: The case for the first derivative of reflectance near $690 \mathrm{~nm}$. Photogramm. Eng. Remote Sens. 1996, 62, 195-200. 
48. Gitelson, A.A.; Laorawat, S.; Keydan, G.P.; Vonshank, A. Optical Properties of dense algal culture outdoors and their application to remote estimation of biomass and pigment concentration in Spirulina Platensis (Cyanobacteria). J. Phycol. 1995, 31, 828-834. [CrossRef]

49. Kim, K.; Mun, H.; Shin, H.; Park, S.; Yu, C.; Lee, J.; Yoon, Y.; Chung, H.; Yun, H.; Lee, K.; et al. Nitrogen stimulates Microcystisdominated blooms more than phosphorus in river conditions that favor non-nitrogen-fixing genera. Environ. Sci. Technol. 2020, 54, 7185-7193. [CrossRef] [PubMed]

50. Kim, H.; Jang, S.; Yoon, H. Utilization of unmanned aerial vehicle(UAV) image for detection of algal bloom in Nakdong River. J. KIECS 2017, 12, 457-463.

51. Jung, W.; Jo, B.; Kim, Y.; Kim, S. A study on the characteristics of cyanobacteria in the mainstream of Nakdong River using decision trees. J. Wet. Res. 2019, 21, 312-320.

52. Choi, J.; Min, J.; Choi, B.; Kang, J.; Choi, K.; Lee, S.; Shin, K. Variation of primary productivity and phytoplankton community in the weirs of mid and downstream of the Nakdong River during fall and early winter: Application of phytoplankton pigments and CHEMTAX. Korean Soc. Limnol. 2019, 52, 81-93. [CrossRef] 